\title{
1 Saponin profile of wild asparagus species
}

2

3 Sara Jaramillo-Carmona ${ }^{1}$, Rocío Rodríguez-Arcos ${ }^{1}$, Ana Jiménez-Araujo ${ }^{1}$,

4 Sergio López ${ }^{2}$, Juan $\mathrm{Gil}^{3}$, Roberto Moreno ${ }^{3}$, Rafael Guillén-Bejarano ${ }^{1, *}$

5

6

$7 \quad{ }^{1}$ Phytochemicals and Food Quality Group, Instituto de la Grasa (CSIC), 41013

8 Seville, Spain

$9{ }^{2}$ Laboratory of Cellular and Molecular Nutrition, Instituto de la Grasa (CSIC),

1041013 Seville, Spain

$11{ }^{3}$ Department of Genetics, University of Córdoba, Campus de Rabanales,

12 Cordoba, Spain

13

15 *Telephone number 954611550; Fax number 954616790; E-mail: rguillen@cica.es 
The aim of this work was to study the saponin profiles from spears of different wild asparagus species in the context of its genetic diversity aside from geographical seed origin. They included Asparagus pseudoscaber Grecescu, $A$. maritimus

(L.) Mill., $A$

A. brachiphyllus Turcz.,

A. prostrates Dumort. and $A$. officinalis L. The saponin analysis by LC-MS has shown that saponin profile from wild asparagus is similar to that previously described for triguero asparagus from Huétor-Tájar landrace (triguero HT), which had not ever been reported in the edible part of asparagus. All the samples, except $A$. officinalis, were characterized for having saponins distinct to protodioscin and the total saponin contents were 10 -fold higher than those described for commercial hybrids of green asparagus. In particular, A. maritimus from different origins were rich in saponins previously found in triguero HT. These findings supported previous suggestion, based on genetic analysis, about $A$. maritimus being the origin of triguero HT. Multivariate statistics including Principal Component Analysis and hierarchical clustering analysis were used to define both similarities and differences among samples. The results showed that the greatest variance of the tested wild asparagus could be attributed to differences in the concentration of particular saponins and this knowledge could be a tool for identifying similar species.

KEYWORDS: wild asparagus; saponins; HPLC-MS, principal component analysis; phytochemical profile 


\section{Introduction}

The worldwide consumption of wild vegetables has played an important role in complementing staple agriculture foods (Morales and others 2012). Although the traditional use of non-cultivated vegetables has decreased with the development of agriculture and global supply chains, some species are still consumed. Indeed, an increasing interest in wild edible plants has been observed in modern societies, due to the fact that wild species are considered a great potential source of unusual flavors and because of their nutritional and pharmaceutical properties (Ertuğ 2004; Ogle and others 2004; Tardío and others 2006; Barucha and Pretty 2010; Sánchez-Mata and others 2011).

Among wild plants, the Asparagus genus has a relevant position, including over 250 species of both food and medicinal interest (Bozzini 1959). Although $A$. officinalis $\mathrm{L}$. is the only cultivated asparagus nowadays, other wild species are edible and traditionally consumed. Wild asparagus is considered a healthy food and used in folk medicine as a diuretic to treat several kidney related disorders (Guarrera and Savo 2013). Nowadays, there is an increasing scientific interest in studying the health benefits of these wild asparagus because not only their nutritional properties, but also their richness in bioactive compounds with demonstrated health-promoting properties (García-Herrera and others 2014; Ferrara and others 2011) such as carotenoids, phenols, saponins, ascorbic acid and other organic acids, among others (Tardío and others 2016; Morales and others 2012; Sánchez-Mata and others 2011; Guillén and others 2008)

On the other hand, several studies have shown that the contents and the types of phenols and fatty acids are higher in wild asparagus than in cultivated one (Morales and others 2012; Guillén and others 2008). In the same way, it 
has been observed that the carotenoid content is higher in wild asparagus and it has been reported significant differences among distinct species (GarcíaHerrera and others 2014).

Saponin content may be affected by the season, the climate and altitude, the plant organ (shoots, roots, fruits, flowers) and the species of Asparagus genus (Negi and others 2011). Similarly, it is known that the saponin content is higher in white asparagus than in green one (Lee and others 2010). In 2000, the European Commission registered the triguero Huétor Tájar (triguero HT) asparagus as Protected Geographical Indication in the European Union (European Commission, 2000). The triguero HT asparagus, also known as "triguero", is the only tetraploid asparagus cultivar, together with the Italian "Violetto d'Albenga" in Europe (Moreno and others 2006). Previous studies on strain identification and phylogeny have suggested that the triguero HT asparagus is close to $A$. officinalis and $A$. maritimus (Moreno and others $2008 a, b)$. Our studies have revealed that among green asparagus, the total saponin content was much higher in triguero HT than in commercial hybrids (CH) (Vázquez-Castilla and others 2013a). However, the information about the saponin profile in wild asparagus is scarce (Negi and others 2011).

The most significant sources of saponins in human diet are triterpenoid types from the legumes such as soybeans and chick peas, typically described in cultivated crops. Steroids saponins are less common and can be found in foods such as asparagus and yucca. The structure of saponins provokes a characteristic behavior at hydrophobic-hydrophilic interfaces and subsequently on membrane cell permeabilisation which is critical for it activity (Sudji and others 2015). In fact, the consumption of saponins is associated to reduced plasma cholesterol concentrations (Harwood and others 1993) and then the risk 
of coronary heart diseases. Other important activity described for saponins is the induction of cancer cell death through different pathways, including apoptosis (Lorent and others 2014). These important beneficial health activities, among others, support the interest of finding new sources of saponins in human diet.

In a previous work, we have developed a new LC-MS method, requiring fairly simple equipment and yielding a clean mixture of saponins that were easily resolved and quantified (Vázquez-Castilla and others 2013a). The results showed that the proposed method can be useful for the profiling of saponin in different asparagus genotypes and, therefore, for the differentiation of asparagus types (Vázquez-Castilla and others 2013a,b). Commercial hybrids and white asparagus are characterized as mostly having an unique steroidal saponin furostanol type, protodioscin, which is a glycoside derivative of diosgenin (Lee and others 2010; Vázquez-Castilla and others 2013a). However, when we have studied the flavonoids and saponin composition from different triguero HT germ plasm genotypes we have found that triguero HT asparagus has a distinct flavonoid and saponin profile compared to $\mathrm{CH}$ (Vázquez-Castilla and others 2013a,b; Fuentes-Alventosa and others 2008). Obtained results revealed that, while $\mathrm{CH}$ contains protodioscin and rutin as the major saponin and flavonoid respectively, triguero HT presents a more complex profile. This consists on a combination of protodioscin and at least twelve different new saponins derived from a furostanol-type steroidal genin with a single bond between $\mathrm{C} 5$ and $\mathrm{C} 6$ of the $\mathrm{B}$ ring, in addition to eight different flavonoids and a lack or very low content of rutin. It is interesting to point out that the morphological characteristics of triguero $\mathrm{HT}$ asparagus are similar to those found in wild asparagus: thinner and bitter spears, shorter cladodes, slightly and 
striated stems. All these characteristics of the different triguero HT genotypes might be related to the fact, pointed out for some authors, that the HT landrace could be a hybrid between cultivated diploid varieties of $A$. officinalis and wild $A$. maritimus (Moreno and others 2008a).

The aim of this research was to study the saponin profile present in the wild asparagus spears from different species in order to find relationships between the wild species and triguero HT landrace.

\section{Materials and methods}

\section{Plant material}

The samples evaluated consisted on spears from 5 species of wild asparagus (A. pseudoscaber Grecescu, A. maritimus (L.) Mill., A. brachiphyllus Turcz., A. prostratus Dumort. and A. officinalis L.). Each seed samples were collected from different geographical localization. Samples of $A$. officinalis and A. brachyphyllus were from Russia, A. pseudoscaber from Czechia, A. prostratus from Spain (Galicia) and A. maritimus seeds, due to its abundance, were collected in different places, such as Italy (Padova and Venice), Albania and Spain (Cartagena). All the spears were harvested from experimental fields (Córdoba, Spain) and immediately transported to the laboratory where they were trimmed to a final length of $21 \mathrm{~cm}$, weighed and frozen at $-20{ }^{\circ} \mathrm{C}$. All samples were harvested in the same experimental fields in order to eliminate the variables related to environmental and agronomic conditions.

\section{Chemicals and reagents}



were purchased from Chromadex Chemical Co. (Barcelona, Spain). Ethanol, 144 formic acid (96\%) and acetonitrile, high-performance liquid chromatography (HPLC) grade, were purchased from Sigma Chemical Co. (St. Louis, MO, USA). Pure deionized water was obtained from a MiliQ50 system (Millipore Corporation, Bedford, MA 01730 U.S.A.).

\section{Saponin extraction}

Samples, consisting of $25 \mathrm{~g}$ of fresh material, were extracted with $100 \mathrm{~mL}$ of $80 \%$ ethanol in an Ultraturrax (T25) (IKA-Labortechnik, Staufen, Germany) for 1 minute at maximum speed and filtered. The residue was extracted again in the same conditions. The ethanol extracts were pooled together and evaporated to dryness at reduced pressure. All extractions were made in triplicate. The dried ethanol extract was re-dissolved in $50 \mathrm{~mL}$ of $\mathrm{EtOH} 80 \%$ and $1 \mathrm{~mL}$ of this dissolution was centrifuged at $12.000 \mathrm{rpm}$ for $3 \mathrm{~min}$ and injected into the HPLCMS system.

\section{Saponin analysis by HPLC-MS}

The method for saponin analysis was developed by our research Group and was described previously in detail (Vázquez-Castilla and others., 2013a). Briefly, a HPLC Waters Alliance system fitted to a MEDITERRANEAN SEA18 reverse-phase analytical column (25 cm length $x 4.6 \mathrm{~mm}$ id., $5 \mu \mathrm{m}$ particle size; Teknokroma, Barcelona) was used. An elution gradient was used with solvent A (water with $1 \%$ formic acid) and B (acetonitrile with $1 \%$ formic acid): $0-30 \mathrm{~min}$, $20 \% \mathrm{~B} ; 30-60 \mathrm{~min}$, linear gradient to $30 \% \mathrm{~B} ; 60$ to 70 min linear gradient to $100 \%$ B and $70-80$ min, linear gradient $20 \%$ B. 
The saponins were detected using an on-line connected quadrupole

167 mass analyzer (ZMD4, Micromass, Waters, Inc., Manchester, U.K.).

168 Electrospray ionization (ESI) mass spectra were obtained at ionization energies of 50 and $100 \mathrm{~V}$ (negative mode) and $50 \mathrm{~V}$ (positive mode) with scans from $\mathrm{m} / \mathrm{z}$ 200 to 1200 . Capillary voltage was $3 \mathrm{kV}$; the desolvation temperature was 200 ${ }^{\circ} \mathrm{C}$; source temperature $100{ }^{\circ} \mathrm{C}$ and extractor voltage $12 \mathrm{~V}$. The flow rate was kept at $1 \mathrm{~mL} / \mathrm{min}$ and a split ratio of $5: 1$ for each analysis.

\section{Quantitative analysis}

The external standard method was used for the quantification of asparagus saponins (Vázquez-Castilla and others., 2013a). For each standard, the selected ion chromatogram corresponding to its molecular ion in negative mode at $100 \mathrm{~V}$, was integrated and the peak area was plotted against concentration and subjected to regression analysis.

\section{Statistical analysis}

Results were expressed as mean value \pm standard deviation. To assess for differences in the total content of saponins in the different species, a multiple sample comparison was performed using the Rcmdr package, $\mathrm{R}$ software v2.15.2. (Available at www.r-project). Multivariate analysis of variance (ANOVA), followed by Duncan's multiple comparison test, was performed to contrast the groups. The level of significance was $p<0.05$. Two matrices were to display maximum variance in a data profile by finding a linear combination of the initial variables. Each component in the PCA model is characterized by two 
attribute percentages of variance, describing the correlations of variables, and eigenvalues describing differences or similarities among the samples. The analysis was conducted using an Rcmdr package, $\mathrm{R}$ software v2.15.2. (Available at www.r-project.), the level of $\mathrm{P}<0.05$ being considered significant.

\section{Results}

\section{Saponin profile of wild asparagus}

In this study, some of the most important wild asparagus species in Europe have been analyzed, as described in "Plant material" section. The identification of saponins was made by the method that we have previously developed (Vázquez-Castilla and others 2013a). This is based on assigning molecular ions tandem MS fragments by the application of a liquid chromatography-mass spectrometry (LC-MS). This methodology allowed the detection of several peaks, which were classified by their retention time, molecular weight and fragmentation pathway, and as well as the co-injection with authentic reference saponins previously purified and identified from triguero HT (Vázquez-Castilla and others 2013a,b). The fragmentation pathway has been studied through the mass spectra obtained in negative (100 V-) and positive $(50 \mathrm{~V}+)$ modes and showed that the pattern of saponins from wild species is similar to that described for different asparagus genotypes of triguero HT. However, A. officinalis, both from wild and cultivated spears, is characterized by protodioscin as unique saponin present likewise it has been described in CH (Table 1) (Vázquez-Castilla and others 2013a,b).

As it can be observed in Table 1, A. prostratus contained a mixture of protodioscin and HTSAP-4. The saponin profile of $A$. maritimus from different 
geographical localization seed mainly consisted on saponins previously

217 reported for triguero $\mathrm{HT}$, which are accompanied by a minor saponin (WSAP-3).

218 This compound presented the same molecular weight and pathway

219 fragmentation model as that previously reported for the HTSAP-6 from triguero HT (Vázquez-Castilla and others 2013a,b), although it presented different

221 retention time, (WSAP-3 $\mathrm{Rt}=34.7 \mathrm{~min}$ vs HTSAP-6 $\mathrm{Rt}=25.03$ ). In addition, those have been detected other three tentative saponins (WSAP-1, WSAP-2, and WSAP-4) with a molecular weights that have not been previously described.

The mass spectra of WSAP-1 (Figure 1) in negative and positive modes were compatible with a saponin containing two deoxyhexose and three hexoses. Figure 1A showed the product ions originated in negative mode from the molecular ion [M-H] $^{-}(\mathrm{m} / \mathrm{z} 1211)$ by loss of either a deoxyhexose $\mathrm{m} / \mathrm{z} 1065$ or a hexose $\mathrm{m} / \mathrm{z} 1049$. The ion $\mathrm{m} / \mathrm{z} 903$ was originated from the loss of a hexose from the ion $\mathrm{m} / \mathrm{z} 1065$ or a deoxyhexose from the ion at $\mathrm{m} / \mathrm{z} 1049$. The ion at $\mathrm{m} / \mathrm{z} 757$ was originated from the loss of a deoxyhexose, the ion at $\mathrm{m} / \mathrm{z}$ 595 from the loss of a hexose and the ion at $\mathrm{m} / \mathrm{z} 433$ (deprotonated genin) from another hexose loss. In the case of the positive spectrum mode (Figure 1B), it showed the ions at $\mathrm{m} / \mathrm{z} 1235$ (sodium adduct $\mathrm{m} / \mathrm{z} 1195$ and loss of one $\mathrm{H}_{2} \mathrm{O}$ molecule) and the ions at m/z 1049, m/z 887, m/z 725, m/z 579 and m/z 417 corresponding to the loss of a deoxyhexose, two hexoses and two deoxyhexoses, respectively.

The second peak, named WSAP-2, had a sugar fragmentation order similar to WSAP-1 (Figure 2). In the spectrum in negative mode (Figure 2A), ions could be seen at m/z 903, m/z 757, m/z 595 and m/z 433 (deprotonated genin) resulting from consecutive losses of a hexose, a deoxyhexose, a hexose and a hexose, respectively. Similarly, in the positive mode spectrum (Figure 2B) 
242 ions appeared at m/z 1089 (sodium adduct molecule), m/z 1049 (loss of one

$243 \mathrm{H}_{2} \mathrm{O}$ molecule) and ions at $\mathrm{m} / \mathrm{z} 903, \mathrm{~m} / \mathrm{z} 741, \mathrm{~m} / \mathrm{z} 579$ and m/z 417 resulting 244 from the loss of a deoxyhexose, a hexose, a hexose and a hexose, 245 respectively.

For A. maritimus from Cartagena (Spain) and Albania these new tentative saponins represented approximately $15 \%$ of the total content (WSAP-4 and WSAP-1 respectively). However, it is remarkably that in $A$. maritimus from Venice, A. pseudoscaber and A. brachiphyllus the main saponin was the new saponin, named WSAP-4. This compound could be also a furostanol saponin as shown by the prominent $\left[\mathrm{M}+\mathrm{H}-\mathrm{H}_{2} \mathrm{O}\right]+$ ion $(\mathrm{m} / \mathrm{z} 861)$ in the positive mode. Unlike the previously described saponins in the negative mode, no fragmentation ions were detected (Figure 3A). In the positive mode (Figure 3B) there was some fragmentation but only two sugars could be identified, so it was not possible to provide a tentative composition for this novel saponin. spears

The saponins from eight lines of wild asparagus from different geographical origin seeds were determined and quantified by the proposed LCMS method under the conditions previously described. The two available commercial standards were protodioscin and shatavarin IV: the first is a furostanoid saponin with a double bond between carbons 5 and 6 in the B-ring, and the latter is a spirostanoid saponin with a single bond between carbons 5 and 6 of the B-ring (Figure 4). It is remarkable that in the method that we have used they have the same response factor (Vázquez-Castilla and others 2013a). 
Since the new saponins are structurally related to both standards, the

quantitative data provided in this study can be considered a good approximation to the real values and, in any case, useful for the purpose of comparison between different wild and cultivated species.

The results showed that there were significant differences in the composition of saponins from the investigated wild asparagus spears (Table 1). The total saponin content of the five species of wild asparagus studied are higher than those described in the $\mathrm{CH}$ and triguero HT (Lee and others 2010; Vázquez-Castilla and others 2013b; Wang and others 2003). Similarly, it has been described that the content for other phytochemicals, such as carotenoids, were higher in wild asparagus than in $\mathrm{CH}$ (García-Herrera and others 2014). The highest values of total saponins were found for $A$. maritimus from respectively). Remarkably, the highest saponin value of $A$. maritimus samples from Cartagena (Spain), revealed that the saponin content was affected not only for species but also by the seed origin. of the saponin profile, we subjected the results to PCA and HCA analyses. A graphical presentation of the PCA results for the two sets of data in the form of biplots is shown in Figure 5. The types of saponins are displayed as vectors. In

PC1 we can see that there is a negative relationship between the presence of WSAP-1, WSAP-2 and HTSAP-12 versus HTSAP-6 and HTSAP-7. In PC2, positive values were associated with the presence of WSAP-3, HTSAP-3 and HTSAP-8, while negative values with the presence of WSAP-4 and HTSAP-1, 
components explained $96 \%$ of the independent saponin composition of the variance in the qualitative data set.

The data were subjected to HCA analysis to assess the heterogeneity among different species (Figure 6). As compared to PCA, HCA allows an interpretation of the results in a fairly intuitive graphical way. The cluster analysis of the different wild asparagus samples, according to saponin profile, showed two clear clusters (cluster 1 and 2). Cluster 1 gathered all samples analyzed but $A$. maritimus from Cartagena (Spain) that constituted cluster 2 with a very different composition. Respect to cluster 1 is constituted for two main groups characterized by the content in HTSAP-8. Cluster 1a referred to species with low content and was constituted for the five species while cluster $1 \mathrm{~b}$ is comprised only by $A$. maritimus from Albania. Inspection of cluster 1a showed that the content in WSAP-4 classified the samples in other two cluster: the $A$. maritimus from Padova (Italy) and Venice (Italy) (cluster 1aa) and the rest of samples (A. brachiphyllus, A. pseudoscaber A. officinalis and A. prostratus) were clustered together (cluster 1ab). Within cluster 1ab, differences in saponin composition are apparently dominant over species. A. prostratus samples were found to be the most closely related to $A$. officinalis being protodioscin also found as the major saponin $(70 \%)$, as showed in Table 1. However, as it will be discussed below, in the rest of the wild asparagus studied, other saponins were predominant and distant from A. maritimus from Albanian samples (cluster 1b).

\section{Discussion}

It has been widely reported in bibliography that the saponin composition is different between wild and cultivated species such as potatoes (Savarese and 
others 2009), leeks (Zolfaghari and others 2006), soybean seeds (Tsukamoto and others 1993) and legumes (Sotelo and others 1995). In the case of the Asparagus genus, important differences were also found. Protodioscin is the main saponin described in the spears of $A$. officinalis (Lee and others 2010; Sharma and others 2009) the only cultivated asparagus species nowadays, while in the wild spears of $A$. racemosus, shatavarin has been found as the main saponin (Sharma and others 2009). We have previously reported that in the spears from triguero $\mathrm{HT}$, saponins were derived from a furostanol genin different from protodioscin (Vázquez-Castilla and others 2013b). In the present study, we have extended the analysis to several species of wild asparagus and the comparison of results with data from our previous studies (Vázquez-Castilla saponin and found the possible relationship between organoleptic and functional role in the different asparagus species. In the present work, we have also found that $A$. officinalis is characterized for containing mostly protodioscin, 
independently if they are cultivated or wild spears. The composition reported for

A. prostratus could be due to the fact that $A$. prostratus is a subspecies from $A$. officinalis as some authors pointed out (Kay and others 2001).

On the other hand, the quantification of saponins from the samples analysed revealed that they contain very high amounts. In fact, as far as we know, these range values have no ever been described in the literature about spears of green asparagus. It is interesting to point out that the triguero HT presents similar saponins derived from a genin type furostanol but their concentrations were between 10 to 100 times lower than those from wild samples (Vázquez-Castilla and others 2013a,b).

These data support the fact that the qualitative and quantitative saponin compositions of plant foods are influenced by cultivar, environmental factors, and plant organ. The saponin profile of all the samples analyzed was subjected to PCA and HCA to determinate the influence of the different factors above cited on the studied phytochemicals. Our results showed that wild sample of $A$. officinalis spears are constituted only by protodioscin, as described from $\mathrm{CH}$ (Lee and others 2010; Vázquez-Castilla and others 2013b; Negi and others 2011) and $A$. prostratus is very similar to $A$. officinalis respect to saponin content. Remarkably, the results provide evidence that $A$. maritimus from Cartagena (Spain), could be possibly new specie that it deserves to be further investigated. In fact, these results are in accordance with those described for Spanish population of $A$. maritimus by others authors (Pedrol and other 2013). They have recently considered as a different species and named as $A$. macrorrhizus Pedrol, Regalado et López-Encina. Possibly, the species used in the present research could be $A$. macrorrhizus Pedrol and not $A$. maritimus. In addition to the different flavonoid profile previously described for this new 
species (Regalado and others 2016), we have shown it has a distinct and

371 characteristic saponin profile too. These could better explain the differences in

372 saponin content found among the Spanish populations of $A$. maritimus

373 investigated in this research.

\section{Conclusions}

In summary, this study has shown important differences in the saponin content of different samples. These differences have been found among the distinct species, especially between $A$. officinalis and the other species. The other major goal of the current study was to investigate these saponin compositions in the context of its genetic diversity aside from geographical seed origin. The results allow us to support the possible genetic origin of triguero HT, which suggested that these spears could be a hybrid between cultivated diploid varieties of $A$. officinalis and wild $A$. maritimus (Moreno and others 2008a). These differences could justify the functional properties which have been attributed to these asparagus from ancient times. So further studies are of interest to determine the possible structure-activity relationship. Results from several works that we have developed during the last decade related to phytochemical composition as new criteria of selection suggest that HT landraces constitute a valuable genetic resource that could help to enlarge the genetic background of modern cultivars. They could be used for the development of new varieties with improved organoleptic, functional, and nutritional characteristics in order to satisfice the worldwide inclination for the consumption of quality natural compounds from plant materials. Moreover, this research could assist in wild asparagus identification from its closely allied species. 
398 Sergio López acknowledges financial support from the Spanish MINECO (JCl399 2012-13084, Juan de la Cierva, MINECO) for his research contract. These 400 contracts are co-funded by the European Social Fund. This work is financed by 401 the Ministerio de Ciencia e Innovación of Spain (AGL2011-29632).

\section{Author's contribution}

Sara Jaramillo-Carmona collected test data, interpreted the results and drafted the manuscript. Rocío Rodríguez-Arcos and Ana Jiménez-Araujo helped to draft the manuscript. Sergio López performed the statistical analyses. Juan Gil and Roberto Moreno provided the samples and made the taxonomic classification. Rafael Guillén-Bejarano' designed the study and interpreted the results.

\section{Abbreviations used}

411 ESI, electrospray ionization; FW, fresh weight; HCA, hierarchical clustering 412 analysis; HT, Huétor-Tájar saponin; HTSAP, Huétor-Tájar saponin, PCA, 413 principal component analysis; PD, protodioscin; Rt; retention time; WSAP, wild 414 saponin

\section{References}

417 Barucha Z, Pretty J. 2010. The roles and values of wild foods in agriculture systems. Phil Trans R Soc B 365: 2913-2926. 
Bozzini A. 1959. Revisione cito-sistematica del genere asparagus L. I: Le specie di asparagus della flora italiana e chiave per la loro determinazione.

421 Cardiologia 12:199-264.

422 Ertuğ,F. 2004. Wild edible plants of the Bodrum Area (Mugla, Turkey). Turk J 423 Bot 28:161-174.

424 European Commission 2000. Commission Regulation (EC) No 547/2000 of 14 March 2000 supplementing the Annex to Regulation (EC) No 2400/96 on the entry of certain names in the "Register of protected designations of origin and protected geographical indications" provided for in Council Regulation (EEC) No $2081 / 92$ on the protection of geographical indications and designations of origin for agricultural products and foodstuffs. Official Journal of the European 430 Communities L67/43:8-11.

Ferrara L, Dosi R, Di Maro A, Guida V, Cefarelli G, Pacifico S, Mastellone C, Fiorentin, A, Rosati A, Parente A. 2011. Nutritional values, metabolic profile and radical scavenging capacities of wild asparagus (A. acutifolius L.). J Food Compos Anal 24:326-333.

Fuentes-Alventosa J, Jaramillo S, Rodríguez-Gutiérrez G, Cermeño P, Espejo JA, Jiménez-Araujo A, Guillén-Bejarano R, Fernández-Bolaños J, Rodríguez-

437 Arcos R. 2008. Flavonoid profile of green asparagus genotypes. J Agric Food 438 Chem 56:6977-6984.

439 García-Herrera P. Cortés M, Cámara C, Tardío J, Olmedilla-Alonso B. 2014. 440 Carotenoid content of wild edible young shoots traditionally consumed in Spain 441 (Asparagus acutifolius L., Humulus lupulus L., Bryonia dioica Jacq. and Tamus 442 communis L.). J Sci Food Agric 94:1914-1916. 
443 Guarrera PM, Savo V. 2013. Perceived health properties of wild and cultivated 444 food plants in local and popular traditions of Italy: A review. J Ethnopharmacol $445 \quad 146: 659-680$.

446 Guillén R, Rodríguez R, Jaramillo S, Rodríguez G, Espejo JA, Fernández447 Bolaños J, Heredia A. 2008. Antioxidants from asparagus spears: Phenolics. 448 Acta Hort 776:246-254.

449 Harwood HJJr, Chandler CE, Pellarin LD, Bangerter FW, Wilkins RW, Long CA, 450 Cosgrove PG, Malinow MR, Marzetta CA, Pettini JL, Savoy YE, Mainet JT. 451 1993. Pharmacologic consequences of cholesterol absorption inhibition: alteration in cholesterol metabolism and reduction in plasma cholesterol concentration induced by the synthetic saponin beta-tigogenin cellobioside (CP88818; tiqueside). J Lipid Res 34:377-95.

Kay QON, Davies EW, Rich TCG. 2001. Taxonomy of the western European endemic Asparagus prostratus (A. officinalis subsp. prostratus) (Asparagaceae). Bot J Linn Soc 137:127-137.

Lee W, Yoo K, Patil B. 2010. Development of a rapid HPLC-UV method for simultaneous quantification of protodioscin and rutin in white and green asparagus spears. J Food Science 75:703-709.

Lorent JH, Quetin-Leclercq J, Mingeot-Leclercq MP. 2014. The amphiphilic nature of saponins and their effects on artificial and biological membranes and potential consequences for red blood and cancer cells. Org Biomol Chem. $12: 8803-22$

465 Morales P, Ferreira I, Carvalho A, Cortés M, Cámara M, Tardío J. 2012. Fatty acids profiles of some Spanish wild vegetables. Food Sci Technol Int 18:281-90. 
Moreno R, Espejo JA, Cabrera A, Millan T, Gil J. 2006. Ploidic and molecular analysis of "Morado de Huétor" asparagus (Asparagus officinalis L.) population: A Spanish tetraploid landrace. Genet Resour Crop Evol 53:729-736.

Moreno R, Espejo JA, Cabrera A, Gil J. 2008a. Origin of tetraploid cultivated asparagus landraces inferred from nuclear ribosomal DNA internal transcribed spacers' polymorphisms. Ann Appl Biol 153:233-241.

Moreno R, Espejo JA, Moreno MT, Gil J. 2008b. Collection and conservation of "Morado de Huétor" Spanish tetraploid asparagus landrace. Genet Resour Crop Evol 55:773-777.

Negi J, Singh P, Pant G, Rawat M. 2011. High performance liquid chromatographic analysis of derivatized sapogenin of asparagus (RP-HOLC analysis of derivatized sapogenin of Asparagus). J Med Plant Res 5:1900-1904.

Ogle BM, Dung NNX, Do TT, Hambraeus L. 2004. The contribution of wild vegetables to micronutrient intakes among women. An example from the Mekong Delta, Vietnam. Ecol Food Nutr 40:159-184.

Pedrol J, Regalado JJ, López-Encina C. 2013. Asparagus L.:Asparagus macrorrhizus (Pedrol, Regalado \& López-Encina), sp. nov., In: Rico E, Crespo MB, Quintanar A, Herrero A, Aedo C (eds) Flora Ibérica, vol XX. Real Jardín Botánico, CSIC, Madrid, 117-119.

Regalado JJ, Moreno R, Castro P, E. Carmona-Martín E, R. Rodríguez R, Pedrol, Larrañaga N, Guillén R, J Gil J, Encina CL. 2016. Asparagus macrorrhizus Pedrol, Regalado et López-Encina, an endemic species from Spain in extreme extinction risk, is a valuable genetic resource for asparagus breeding. Genet Resour Crop Evol 1-14 DOI: 10.1007/s10722-016-0456-2. 
491

492

493

494

495

496

497

498

499

500

501

502

503

504

505

506

507

508

509

510

511

514

512 Ethnobotany and Food Composition Tables. Springer, New York, 273-470.

513 Tardío J, Pardo-de-Santayana M, Morales R. 2006. Ethnobotanical review of

Sánchez-Mata MC, Cabrera RD, Morales $P$, Fernández-Ruiz V, Cámara $M$,

Díez C, Pardo-de-Santaya M, Tardío J. 2011. Wild vegetables of the Mediterranean area as valuable sources of bioactive compounds. Genet Resour Crop Evol 59:431-433.

Savarese S, Andolfi A, Cimmino A, Carputo D, Frusciante L, Evidente A. 2009.

Glycoalkaloids as biomarkers for recognition of cultivated, wild and somatic hybrids of potato. Chem Biodivers 6:437-446.

Sharma U, Saini R, Bobita Y, Kuma RN, Singh, B. 2009. Steroidal saponins from Asparagus racemosus. Chem Pharm Bull 57:890-893.

Sotelo A, Contreras E, Flores S. 1995. Nutritional value and content of antinutritional compounds and toxics in ten wild legumes of Yucatan peninsula. Plant Food Hum Nutr 74:115-123.

Sudji IR, Subburaj Y, Frenkel N, García-Sáez AJ, Wink M. 2015. Membrane Disintegration Caused by the Steroid Saponin Digitonin Is Related to the Presence of Cholesterol. Molecules 20:20146-20160

Tardío J, Sánchez-Mata MC, Morales R, Molina M, García-Herrera P, Morales $P$, Díez-Marqués C, Fernández-Ruiz V, Cámara $M$, Pardo-de-Santayana $M$, Matallana-González MC, Ruiz-Rodríguez BM, Sánchez-Mata D, Torija-Isasa ME, Guil-Guerrero JL, Boussalah N. 2016. Ethnobotanical and Food Composition Monographs of Selected Mediterranean Wild Edible Plants. In: Sánchez-Mata MC, Tardío J (eds) Mediterranean Wild Edible Plants. wild edible plants in Spain. Bot J Linn Soc 152:27-71. 
515 Tsukamoto C, Kikuchi A, Harada K, Kitamura K, Okubo K. 1993. Genetic and

516 chemical polymorphisms of saponins in soybean seed. Phytochem 34:13515171356.

518 Vázquez-Castilla S, Jaramillo-Carmona S, Fuentes-Alventosa JM, Jiménez519 Araujo A, Rodríguez-Arcos R, Cermeño-Sacristán P, Espejo-Calvo JA, Guillén520 Bejarano R. 2013a. Optimization of a method for the profiling and quantification 521 of saponins in different asparagus genotypes. J Agric Food Chem 61:62505226258.

523 Vázquez-Castilla S, Jaramillo-Carmona S, Fuentes-Alventosa JM, Jiménez524 Araujo A, Rodríguez-Arcos R, Cermeño-Sacristán P, Espejo-Calvo JA, Guillén525 Bejarano R. 2013b. Saponin profile of green asparagus genotypes. J Agric 526 Food Chem 61:11096-11108.

527 Wang M, Tadmor Y, Wu QL, Chin CK, Garrison SA, Simon JE. 2003. 528 Quantification of protodioscin and rutin in asparagus shoots by LC/MS and 529 HPLC methods. J Agric Food Chem 51:6132-6136.

530 Zolfaghari B, Barile E, Capasso R, Izzo AA, Sajjadi E, Lanzotti V. 2006. The 531 sapogenin atroviolacegenin and its diglycoside atroviolaceoside from Allium 532 atroviolaceum. J Natural Product 69:191-195. 


\section{TABLES:}

Table 1. Saponin composition and total content in different wild asparagus species.

\begin{tabular}{|c|c|c|c|c|c|c|c|c|c|c|c|c|c|}
\hline & & & & & & & aponins & & & & & & Total content \\
\hline $\begin{array}{l}\text { Asparagus species } \\
\text { (Seed origin) }\end{array}$ & HTSAP-1 & WSAP-1 & HTSAP-3 & HTSAP-4 & PD & WSAP-2 & HTSAP-12 & HTSAP-6 & HTSAP-7 & HTSAP-8 & WSAP-3 & WSAP-4 & $\mathrm{mg} / 100 \mathrm{~g}$ \\
\hline $\begin{array}{l}\text { A. officinalis } \\
\text { (Russia) }\end{array}$ & N.D & N.D & N.D & N.D & $100 a$ & N.D & N.D & N.D & N.D & N.D & N.D & N.D & $2.2 \pm 0.02^{\mathrm{a}}$ \\
\hline $\begin{array}{l}\text { A. pseudoscaber } \\
\text { (Czechia) }\end{array}$ & $0.7 \pm 0.02^{\mathrm{a}}$ & N.D & N.D & N.D & N.D & $1.0 \pm 0.06^{\mathrm{a}}$ & N.D & $1.7 \pm 0.1^{\mathrm{a}}$ & N.D & N.D & N.D & $97 \pm 0.9^{\mathrm{a}}$ & $88.3 \pm 6.6^{b}$ \\
\hline $\begin{array}{l}\text { A. maritimus } \\
\text { (Italy-Venice) }\end{array}$ & N.D & N.D & $1.5 \pm 0.08^{\mathrm{a}}$ & N.D & N.D & N.D & N.D & $11.5 \pm 0.7^{b}$ & $2 \pm 0.1^{\mathrm{a}}$ & N.D & N.D & $85 \pm 2.6^{a}$ & $32.1 \pm 3.4^{b}$ \\
\hline $\begin{array}{l}\text { A. maritimus } \\
\text { (Italy-Padova) }\end{array}$ & N.D & N.D & $2.2 \pm 0.1^{\mathrm{a}}$ & N.D & N.D & N.D & N.D & $77.2 \pm 8.0^{\mathrm{c}}$ & $1.3 \pm 0.3^{\mathrm{a}}$ & $1.3 \pm 0.1^{a}$ & $3.3 \pm 0.3^{\mathrm{a}}$ & $14.7 \pm 1.1^{b}$ & $22.4 \pm 2.0^{b}$ \\
\hline $\begin{array}{l}\text { A. maritimus } \\
\text { (Albania) }\end{array}$ & N.D & N.D & $13 \pm 1.0^{b}$ & N.D & N.D & N.D & $11.5 \pm 1.2^{\mathrm{a}}$ & N.D & N.D & $68 \pm 1.4^{b}$ & $7.8 \pm 1.1^{b}$ & N.D & $16.8 \pm 1.2^{c}$ \\
\hline $\begin{array}{l}\text { A. maritimus } \\
\text { (Spain-Cartagena) }\end{array}$ & N.D & $16.6 \pm 1.3$ & N.D & N.D & N.D & $1.6 \pm 0.09^{\mathrm{a}}$ & $74.3 \pm 3.1^{b}$ & N.D & N.D & $4.5 \pm 0.2^{c}$ & N.D & $3.1 \pm 0.3^{c}$ & $142.7 \pm 13^{b}$ \\
\hline $\begin{array}{l}\text { A. brachiphyllus } \\
\text { (Russia) }\end{array}$ & $1 \pm 0.04^{\mathrm{a}}$ & N.D & N.D & N.D & N.D & N.D & N.D & $2 \pm 0.2 a$ & N.D & N.D & N.D & $96 \pm 3.0^{\mathrm{a}}$ & $224.2 \pm 22.0^{d}$ \\
\hline $\begin{array}{l}\text { A. prostratus } \\
\text { (Spain-Galicia) }\end{array}$ & N.D & N.D & N.D & $25.4 \pm 1.7$ & $74.6 \pm 4.2^{b}$ & N.D & N.D & N.D & N.D & N.D & N.D & N.D & $51.4 \pm 4.1^{\mathrm{b}}$ \\
\hline
\end{tabular}

In each column, values with different letters are significantly different $(P<0.05)$. N.D. Not detected; HTSAP, Huétor-Tájar saponin; WSAP, wild saponin; PD protodioscin 

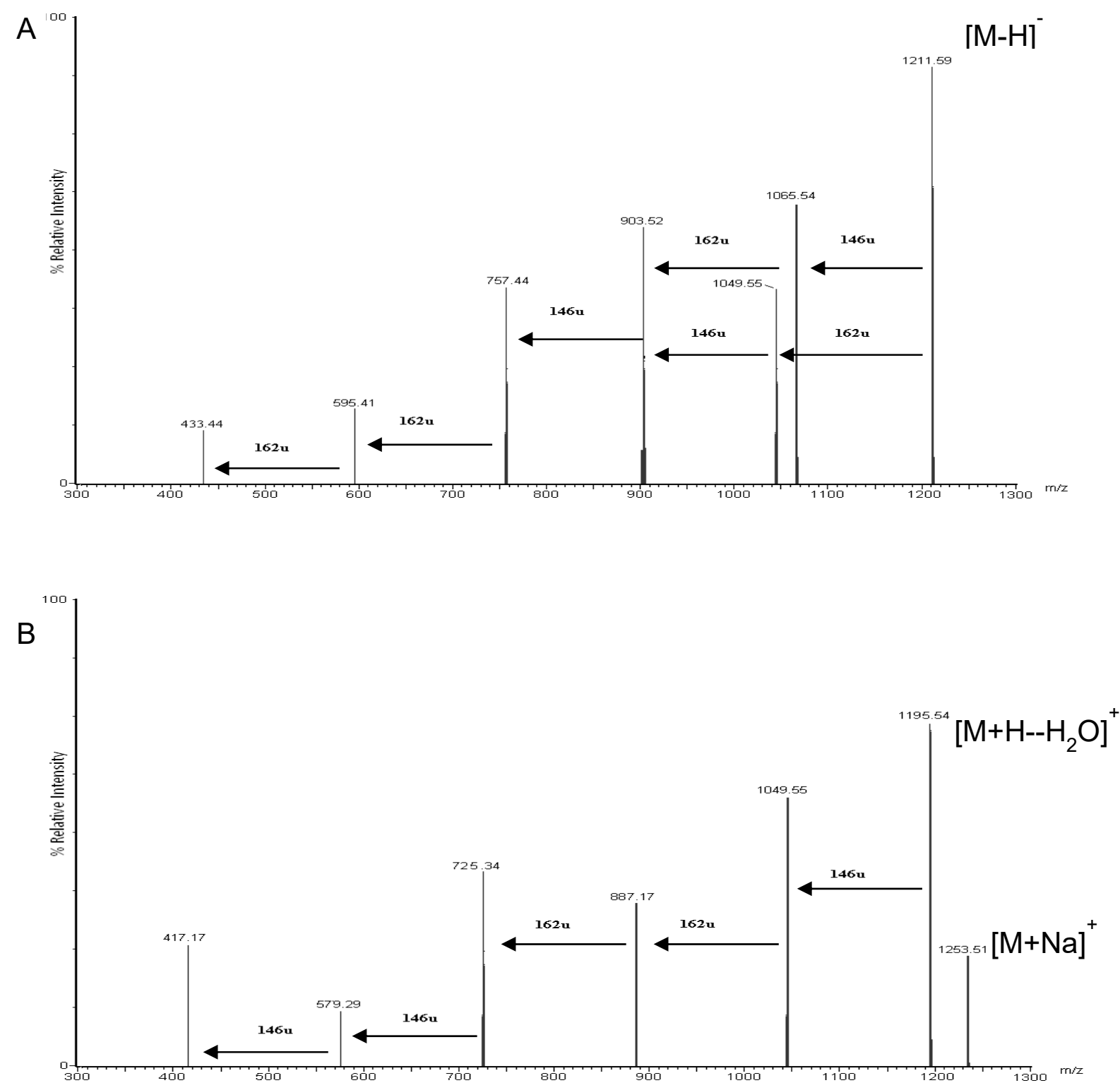

Figure 1 ESI mass spectra of WSAP-1 in negative (A, 100V-) and positive (B, $50 \mathrm{~V}+)$ modes. Arrows indicate the loss of single monosaccharide moieties. 

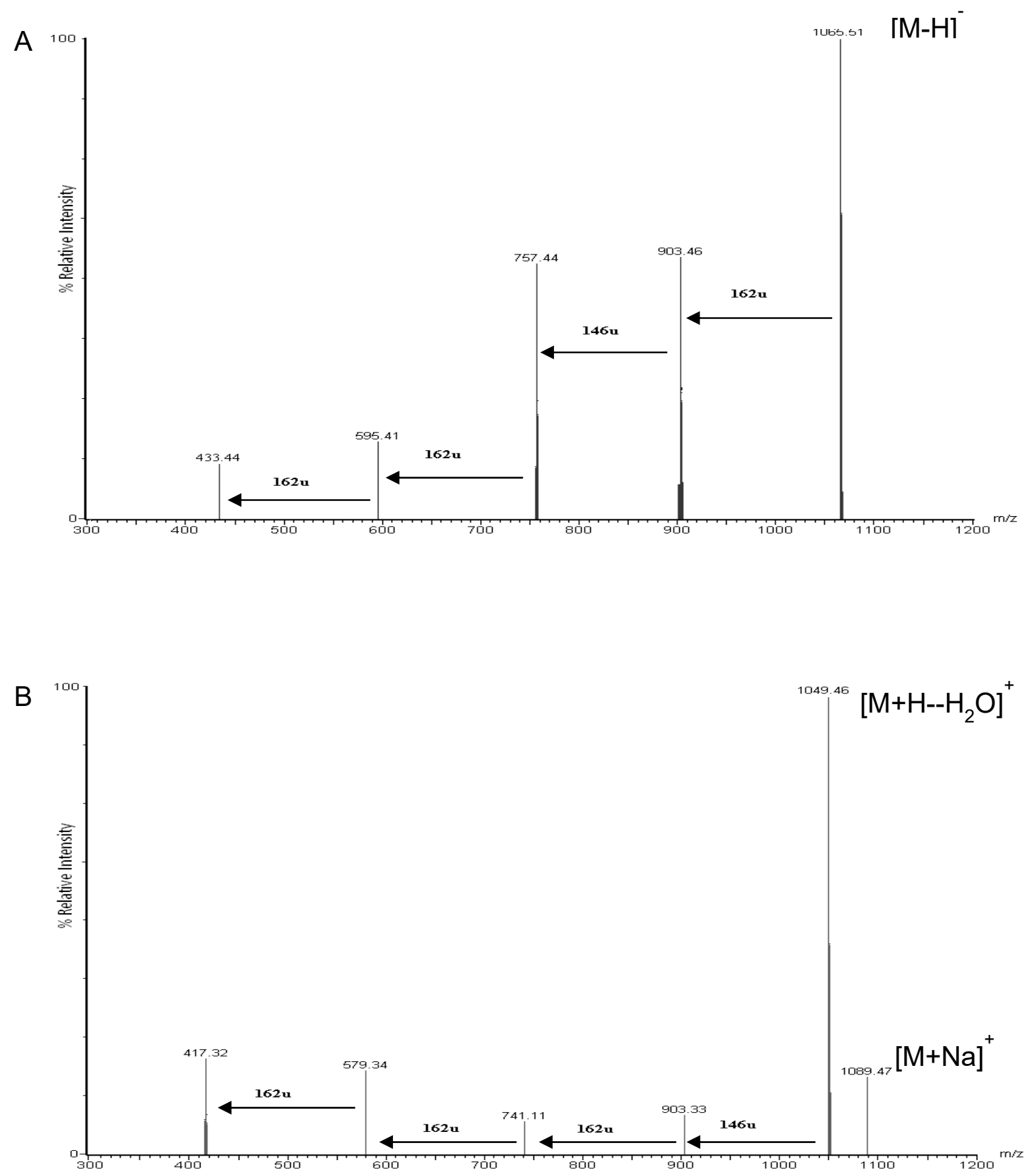

Figure 2 ESI mass spectra of WSAP-2 in negative (A, 100V-) and positive (B, $50 \mathrm{~V}+)$ modes. Arrows indicate the loss of single monosaccharide moieties. 

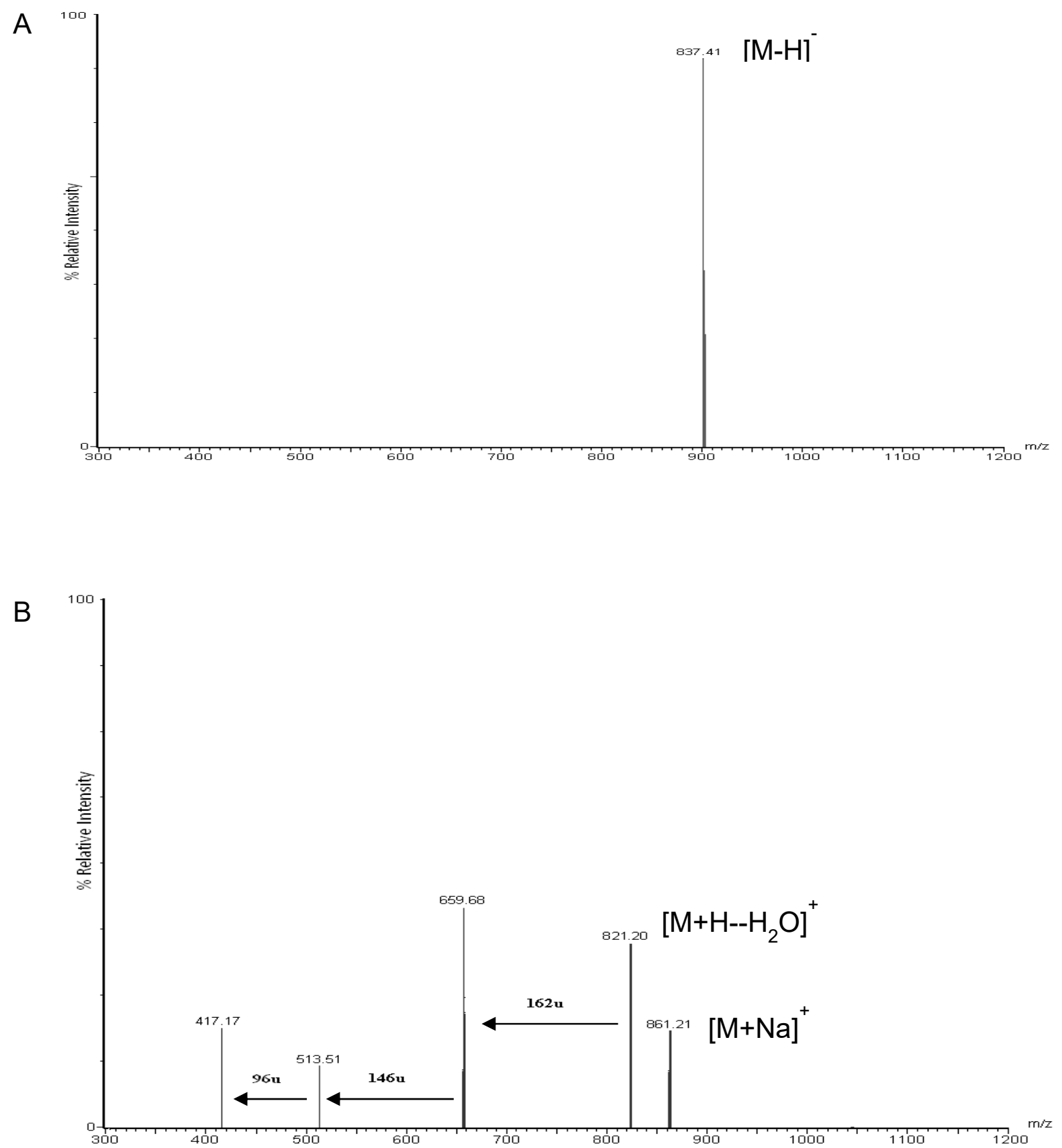

Figure 3 ESI mass spectra of WSAP-4 in negative (A, 100V-) and positive (B, $50 \mathrm{~V}+)$ modes. Arrows indicate the loss of single monosaccharide moieties. 

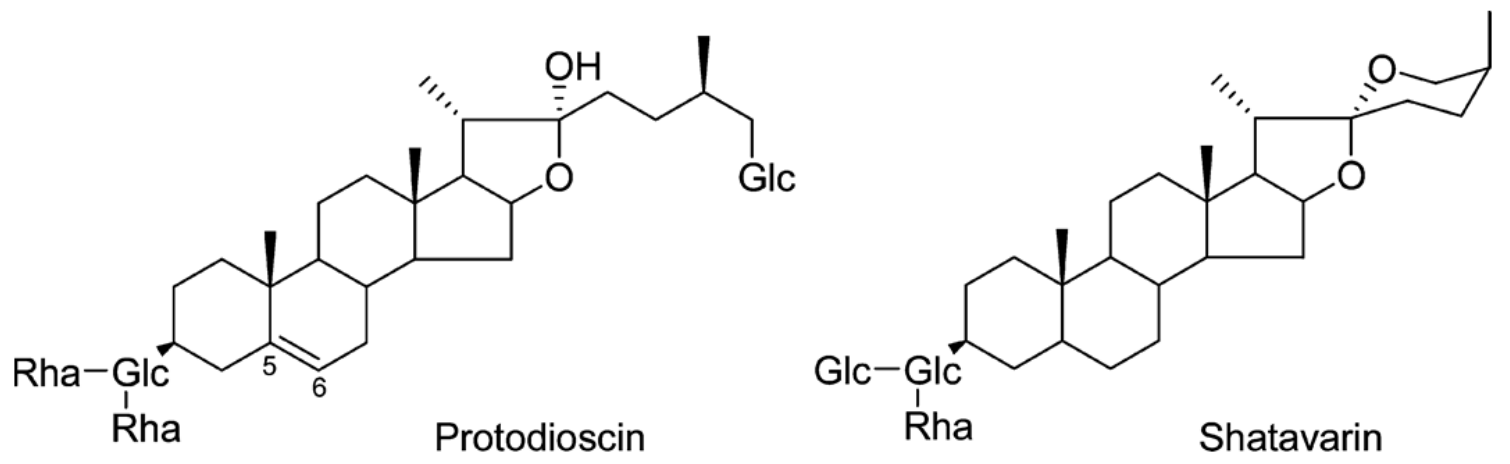

Figure 4 Structures of protodioscin and shatavarin. 


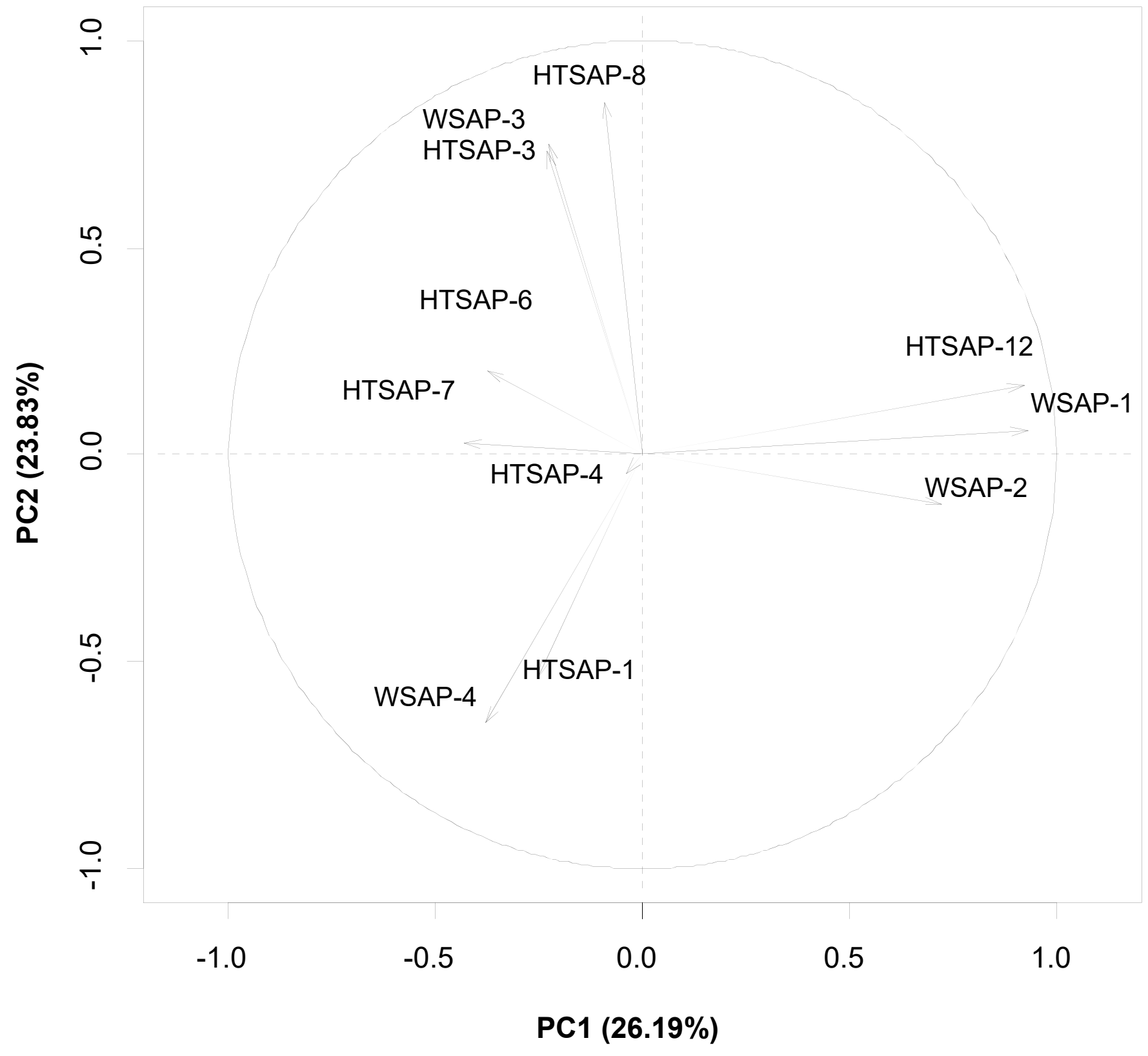

Figure 5 Principal component analyses of saponin profiles of different wild asparagus samples from different seed origin $(n=35)$. 


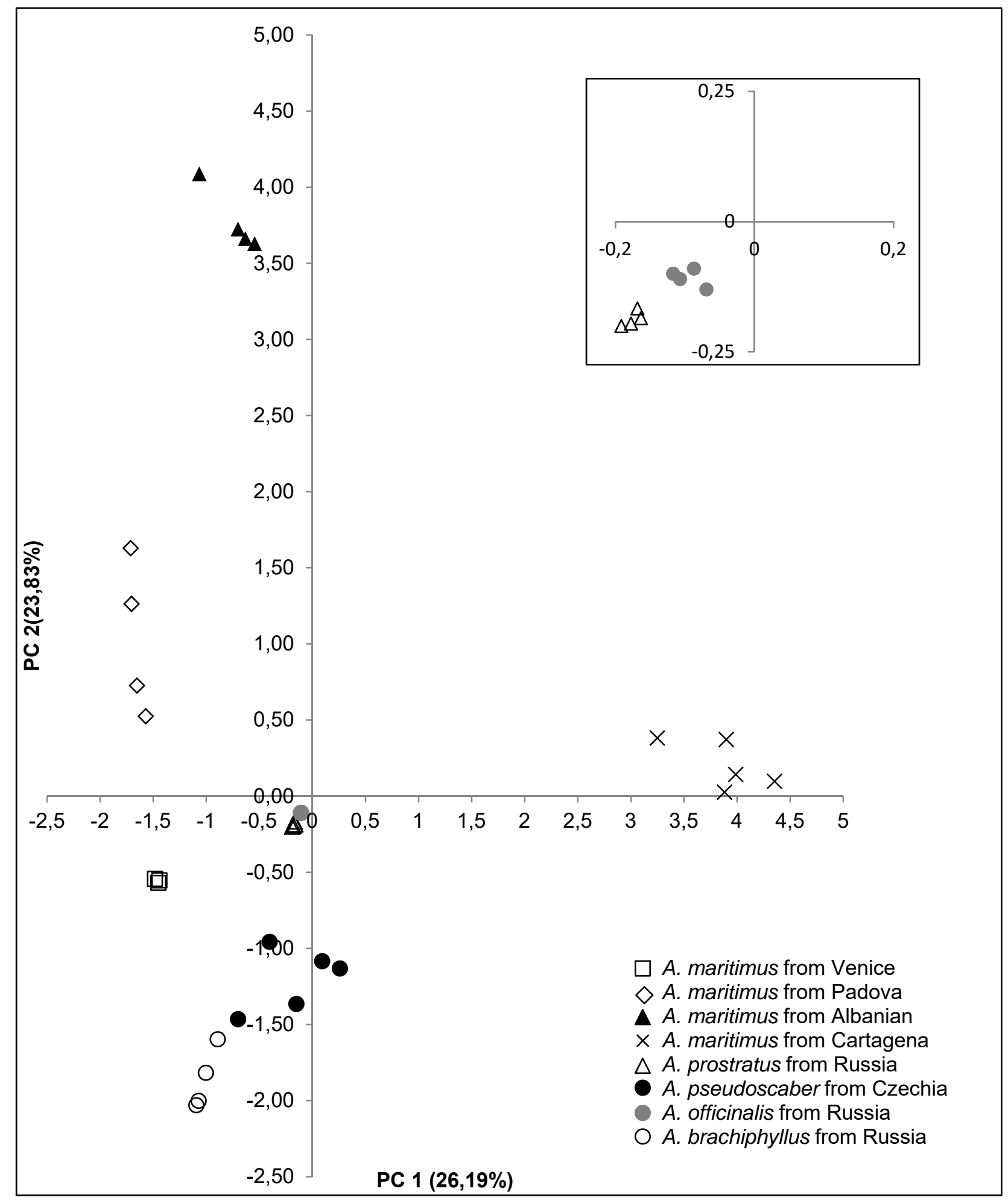

Figure 6 Hierarchical clustering analysis. The wild asparagus species clusters are located at the distinct positions described by two vectors of principal component $1(P C 1=26 \%)$ and principal component $2(P C 2=24 \%)$. Inner Figure: data-zoom-image. 

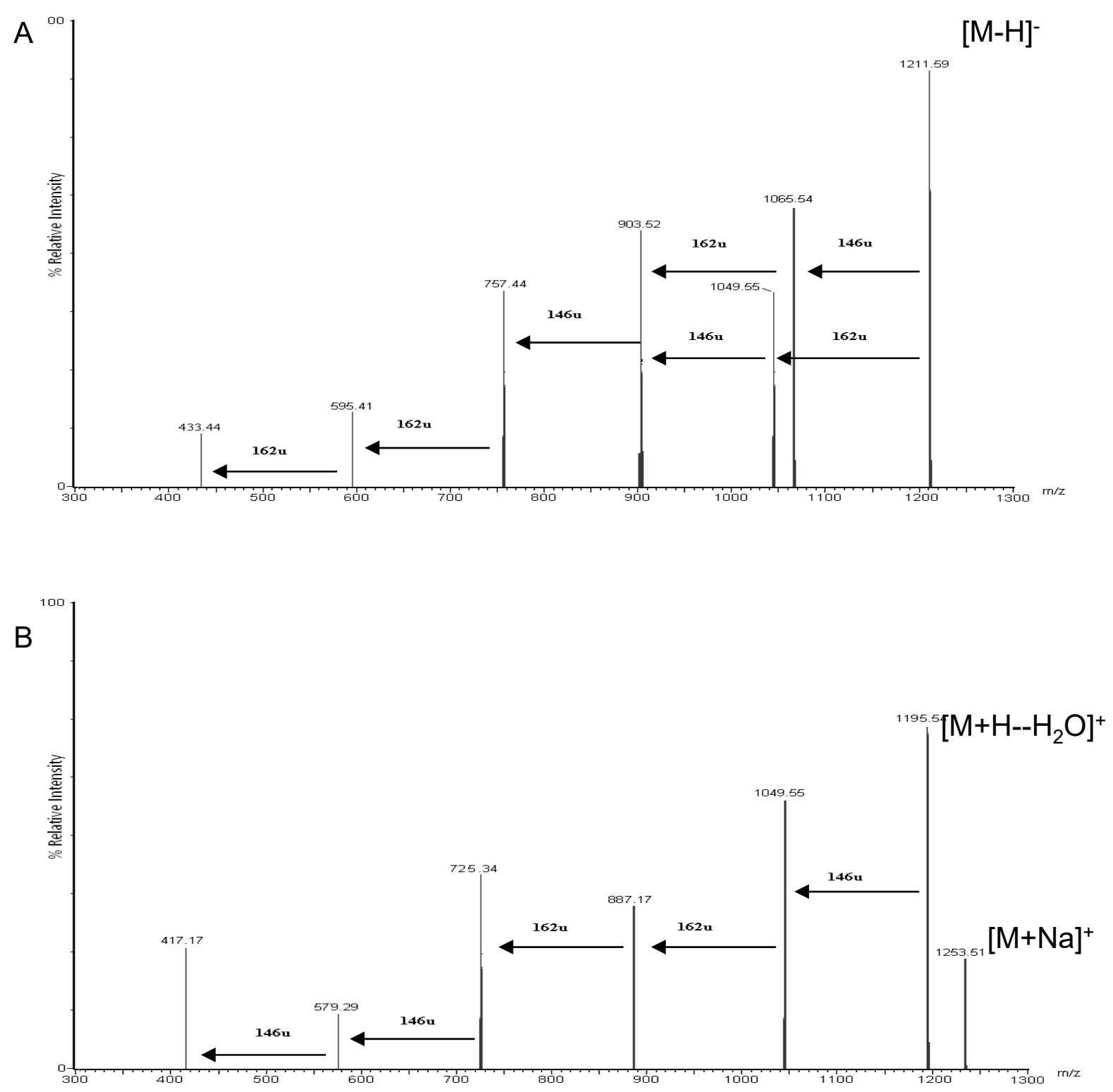

Figure 1 ESI mass spectra of WSAP-1 in negative (A, 100V-) and positive $(B, 50 \mathrm{~V}+)$ modes. Arrows indicate the loss of single monosaccharide moieties. 

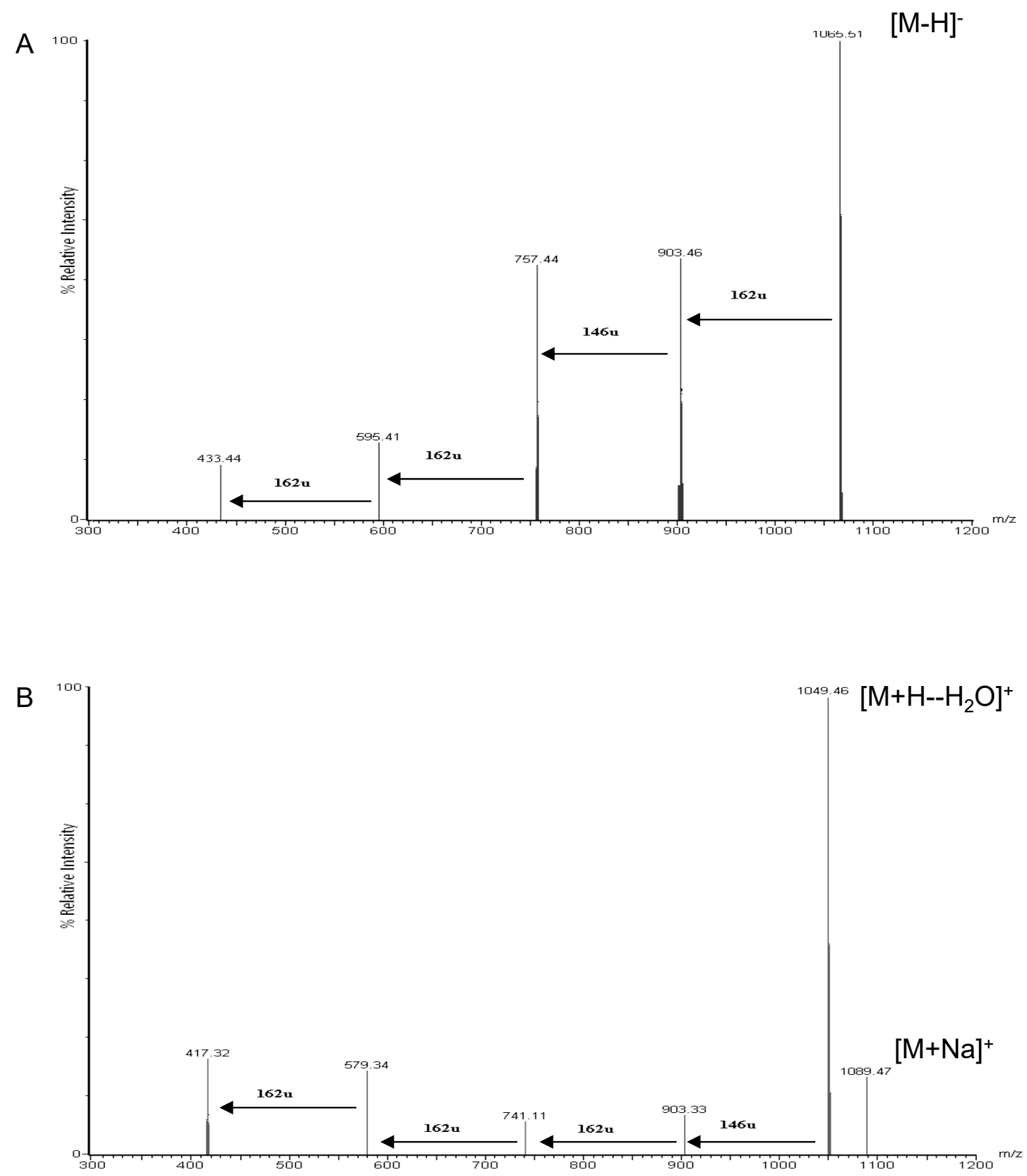

Figure 2 ESI mass spectra of WSAP-2 in negative (A, 100V-) and positive $(B, 50 \mathrm{~V}+)$ modes. Arrows indicate the loss of single monosaccharide moieties. 

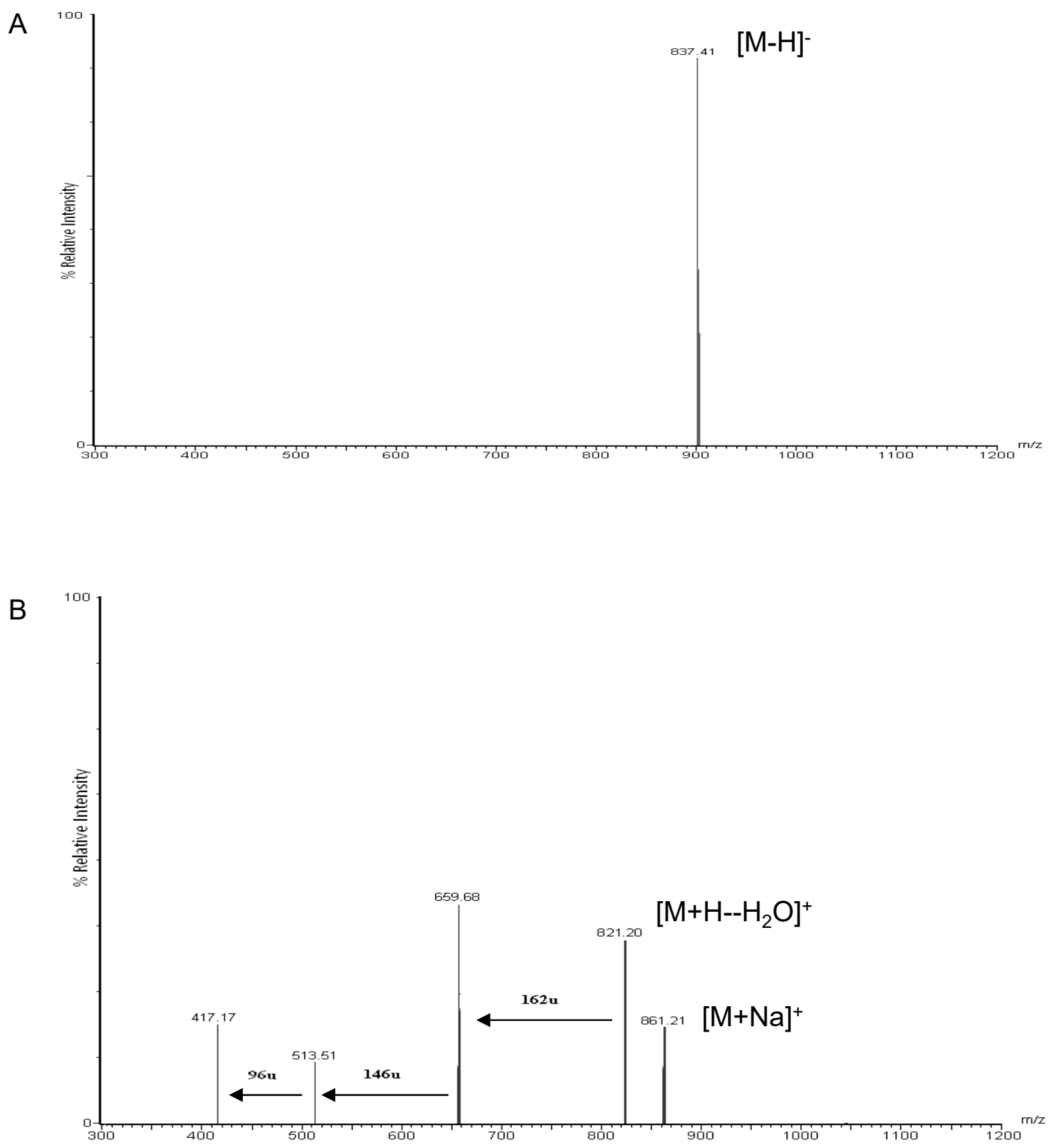

Figure 3 ESI mass spectra of WSAP-4 in negative (A, 100V-) and positive $(B, 50 \mathrm{~V}+)$ modes. Arrows indicate the loss of single monosaccharide moieties. 


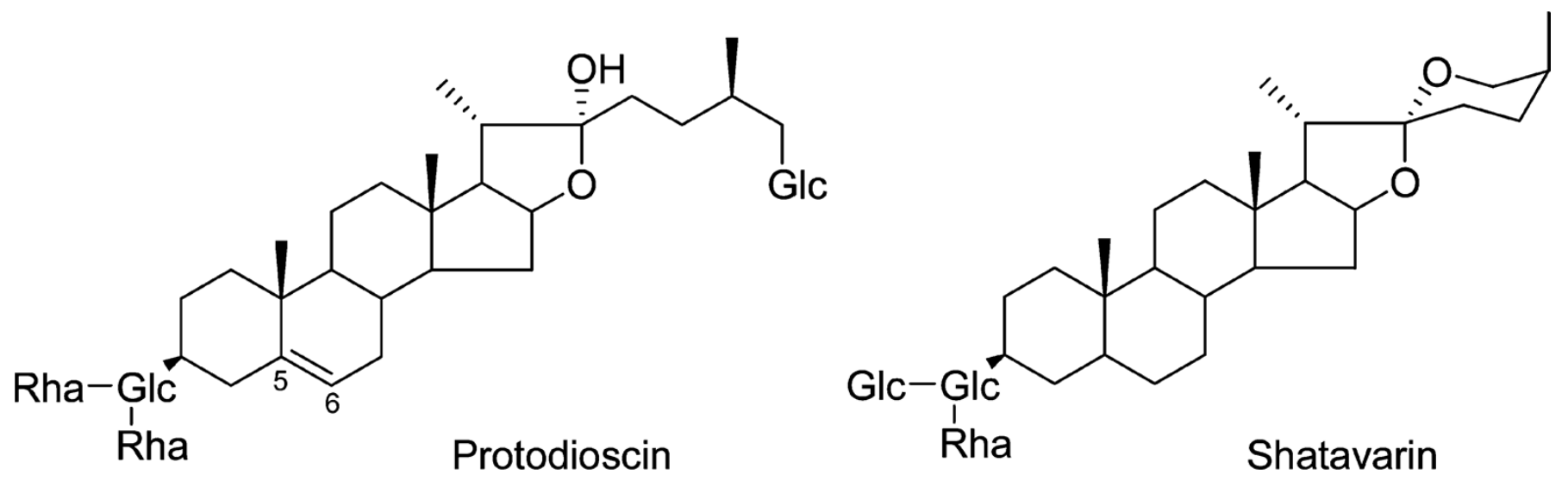

Figure 4 Structures of protodioscin and shatavarin. 


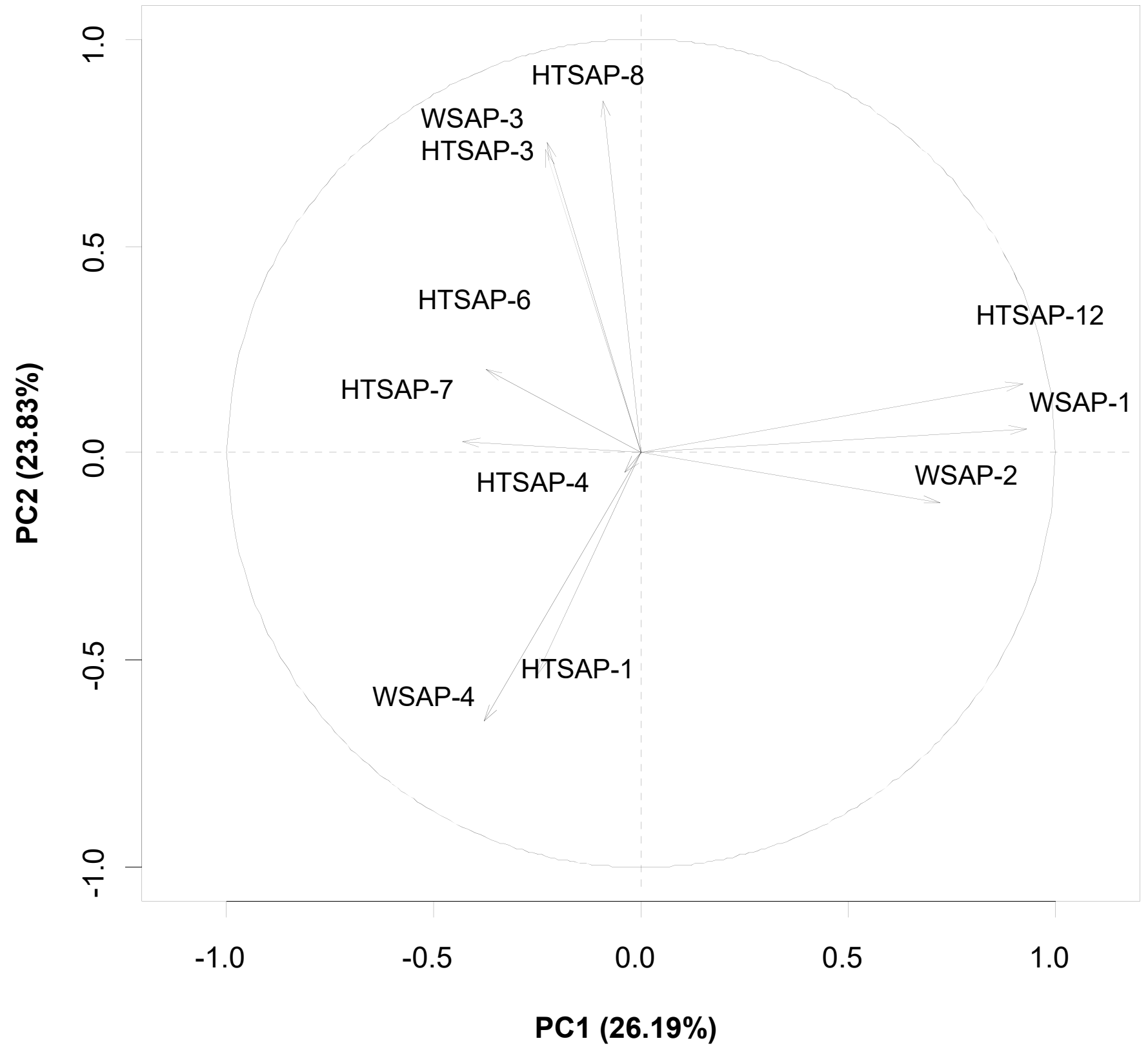

Figure 5 Principal component analyses of saponin profiles of different wild asparagus samples from different seed origin $(n=35)$. 


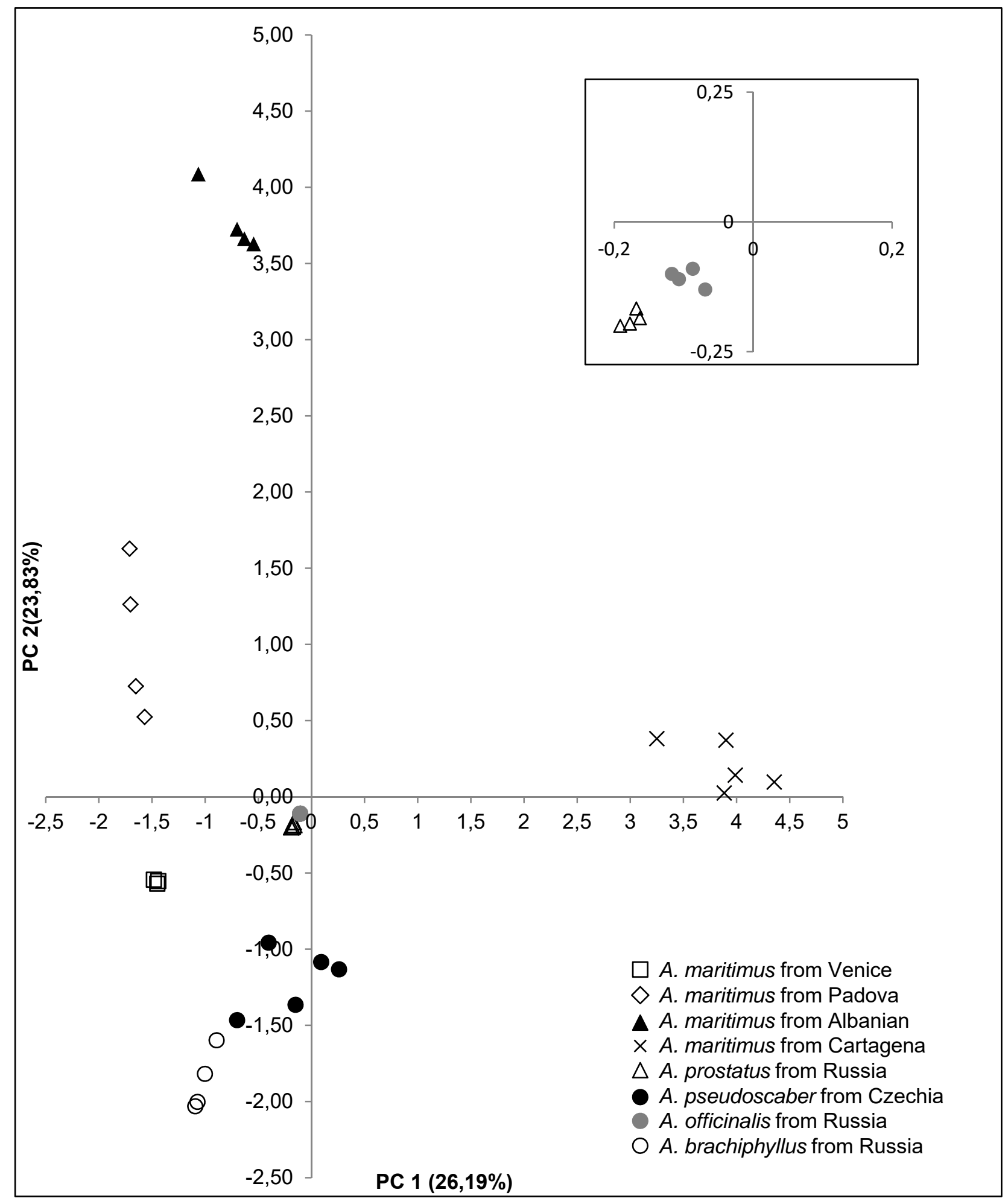

Figure 6 Hierarchical clustering analysis. The wild asparagus specie clusters are located at the distinct positions described by two vectors of principal component $1(P C 1=26 \%)$ and principal component 2 (PC2=24 \%). Inner Figure : data-zoom-image. 